\title{
Recent Advances in the Development of Noble Metal NPs for Cancer Therapy
}

\author{
Rui Zhao, Jia Xiang, Bo Wang ${ }^{(D)}$, Lin Chen, and Songwen Tan $(\mathbb{D}$ \\ Xiangya School of Pharmaceutical Sciences, Central South University, Changsha 410013, China \\ Correspondence should be addressed to Songwen Tan; stan0309@uni.sydney.edu.au
}

Received 24 September 2021; Accepted 8 January 2022; Published 28 January 2022

Academic Editor: Valeria De Matteis

Copyright (C) 2022 Rui Zhao et al. This is an open access article distributed under the Creative Commons Attribution License, which permits unrestricted use, distribution, and reproduction in any medium, provided the original work is properly cited.

\begin{abstract}
With the development of nanotechnology, noble metal nanoparticles are widely used in the treatment of cancer due to their unique optical properties, excellent biocompatibility, surface effects, and small size effects. In recent years, researchers have designed and synthesized a large number of nanomedicines that can be used for cancer treatment based on the morphology, physical and chemical properties, mechanism of action, and toxicological studies of noble metal nanoparticles. Furthermore, the integration of diagnosis and treatment, hyperthermia, cytotoxicity research, and drug delivery system based on the study of noble metal nanoparticles can be used as effective means for cancer treatment. This article focuses on the analysis of noble metal nanoparticles that are widely used in the treatment of cancer, such as gold nanoparticles, silver nanoparticles, platinum nanoparticles, and palladium nanoparticles. The various methods and mechanisms of action of noble metal nanoparticles in the treatment of cancer are objectively summarized in detail. Based on the research on the therapeutic safety and toxicity of noble metal nanoparticles, the development prospect of noble metal nanoparticles in the future clinical application is prospected.
\end{abstract}

\section{Introduction}

Cancer is the biggest enemy of human health at present. According to the global cancer statistics, the mortality rate caused by cancer in China is $24 \%$, and with the increase in the number of patients, China spends more than 220 billion yuan per year on cancer $[1,2]$. Drug therapy (chemotherapy) has a significant therapeutic effect on most tumors. As one of the main effective methods for the treatment of cancer, chemotherapy has significantly improved the survival and quality of life of cancer patients [3]. However, most of the antitumor drugs are nonspecific drugs with large toxic and side effects [4], which can cause drug resistance while seriously damaging the body function of patients [5]. Therefore, the improvement of antitumor drugs with poor water solubility, imperfect absorption in vivo, and low bioavailability has become a hotspot in the research and development of innovative drugs in the field of modern medical research [6].

The emergence of nanodrugs effectively makes up for the shortcomings of traditional anticancer drugs. In 1964, nanoliposomes were first reported for the delivery of antitumor drugs. Researchers found that, compared with traditional antitumor drugs, nanoliposomes had more stable plasma concentration levels and lower toxic and side effects and were significantly superior to traditional drugs in pharmacokinetics and pharmacodynamics [7]. Since then, nano-antitumor drugs have developed rapidly and become a research hotspot due to their outstanding advantages such as controlled release, targeting, high efficiency, and low toxicity [8]. With the development of nanotechnology, noble metal nanoparticles have been widely used in the biomedical field due to their unique optical properties, excellent biocompatibility, surface effect, and small size effect. Based on the definition of nanoparticles, noble metal nanoparticles are defined as particles smaller than $100 \mathrm{~nm}$ in size in at least one dimension [9]. This paper focuses on the noble metal nanoparticles commonly used in the treatment of cancer, including gold nanoparticles, silver nanoparticles, platinum nanoparticles, and palladium nanoparticles, and summarizes the various methods and mechanisms of noble metal nanoparticles in the treatment of cancer in detail, which are briefly described in Figure 1. 


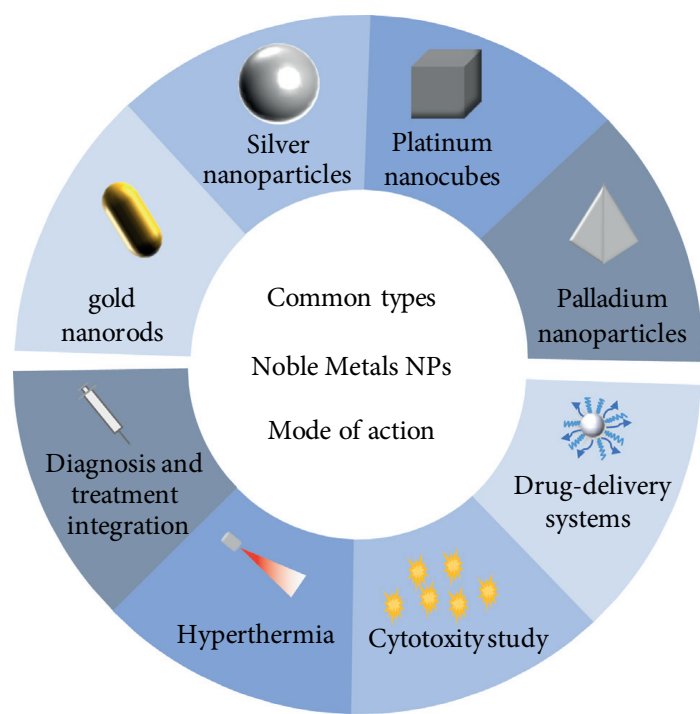

Figure 1: Types and mechanisms of noble metal nanoparticles for cancer therapy.

\section{Types of Noble Metal Nanoparticles for the Treatment of Cancer}

The three-dimensional size of noble metal nanoparticles has at least one-dimensional distribution within $100 \mathrm{~nm} \mathrm{[10].}$ Noble metal nanoparticles are widely used in biomedicine because of their large specific surface area, excellent biological properties, easy preparation, high efficiency, and low toxicity. At present, the noble metal nanoparticles commonly used in the treatment of tumors mainly contain gold, silver, platinum, copper, lead, and other noble metal materials. Through different synthesis conditions, spherical, rod-like, powder, film, and other noble metal nanoparticles with different morphologies can be prepared, such as the chemical method based on the liquid phase sol-gel method [11], as well as laser ablation [12], vacuum sputtering [13], vacuum evaporation method [14], ion implantation method [15], and other physical methods. When the morphology, size, and composition of noble metal nanoparticles change, their physical and chemical properties also change accordingly [16]. For example, spherical gold nanomaterials usually have strong absorption spectra in the visible region, while rod-shaped gold nanomaterials have strong absorption spectra in the near-infrared region. This phenomenon is mainly related to the localized surface plasmon resonance (LSPR) effect of noble metal nanoparticles [17]. Meanwhile, in the LSPR region, the surface-enhanced Raman scattering (SERS) effect [18] and metal-enhanced fluorescence (MEF) effect [19] are also found on the surface of noble metal nanoparticles, which contribute to the unique electronic properties and efficient photothermal conversion of noble metal nanoparticles.

2.1. Gold Nanoparticles. In recent years, based on the excellent properties of gold nanoparticles, the synthesis and application of gold nanoparticles (GNPs) have become a research hotspot. At present, the efficient methods commonly used for the preparation of gold nanoparticles are the electrochemical method [20], two-phase method [21], and seed growth method [22, 23]. In addition, the biosynthesis method [24] is also a new method commonly used for the preparation of gold nanoparticles with good monodispersity and small particle size. With gold as the matrix, different gold nanostructures can be synthesized based on different synthesis methods and different synthesis processes. Common structures of gold nanomaterials include gold nanorods [25], gold nanoprisms [26], gold nanocages [27], etc. The SEM images of gold NPs capped with Croton caudatus Geisel leaf extract obtained by Vijaya Kumar et al. [28] are shown in Figure 2.

Gold nanoparticles are widely used in biomedical fields due to their small particle size, good monodispersity, high tissue permeability, and colloidal stability [29]. They can be used to treat tumors by inhibiting angiogenesis, hyperthermia, and loading antitumor drugs. Studies have successively found that GNPs can act on heparin-binding proteins, such as basic fibroblast growth factor (bF-GF) and vascular endothelial growth factor-165 (VEGF-165) [30], epidermal growth factor receptor (EGFR), and vascular endothelial growth factor receptor-2 (VEGFR-2) [31]; this limits the growth and metastasis of the tumor cells. In contrast, GNPs have no inhibitory effect on non-heparinbinding protein growth factors. On the other hand, GNPs have an LSPR effect, which can effectively absorb light energy in the near-infrared region and convert it into heat energy. Hyperthermia is performed in the tumor site to induce protein denaturation and cell apoptosis, thereby killing the cancer cells [32]. In recent years, the design and synthesis of antitumor drugs that can be used for photothermal therapy have become a research hotspot with gold nanorods (or gold nanospheres) as the matrix and functionalized modification on its surface [33]. Song et al. [34] reported the gold nanorod vesicles (rGO-AuNRVes) loaded with mixed reduced graphene oxide ( $\mathrm{rGO}$ ) and doxorubicin (DOX). The experimental results show that rGO-AuNRVes have excellent photoacoustic (PA) properties and photothermal effects, realizing the combination of hyperthermia and targeted drug delivery. At the same time, gold nanoparticles can also be used as drug carriers, directly or after surface modification combined with drugs through covalent bonds [35] or noncovalent bonds [36], to load a variety of drugs to reach the target site, improve the bioavailability of drugs, and realize the controlled release of drugs. Sun et al. [37] used gold nanorods as the carrier, surface modified with polyethylene glycol (PEG) and $64 \mathrm{Cu}$, and used positron emission tomography (PET) for optical imaging. This drug delivery system showed high targeting ability, which could realize individualized medication and avoid side effects. Table 1 lists the common drug carrier systems using gold nanoparticles for clinical cancer therapy in recent years. In addition, radiation sensitization [45], excellent biocompatibility, and unique optical properties [46] have promoted the integrated development of diagnosis and treatment of gold nanoparticles. However, as a kind of noble metal medical material for cancer therapy, researchers should pay attention to its biological safety and environmental safety. At the same 

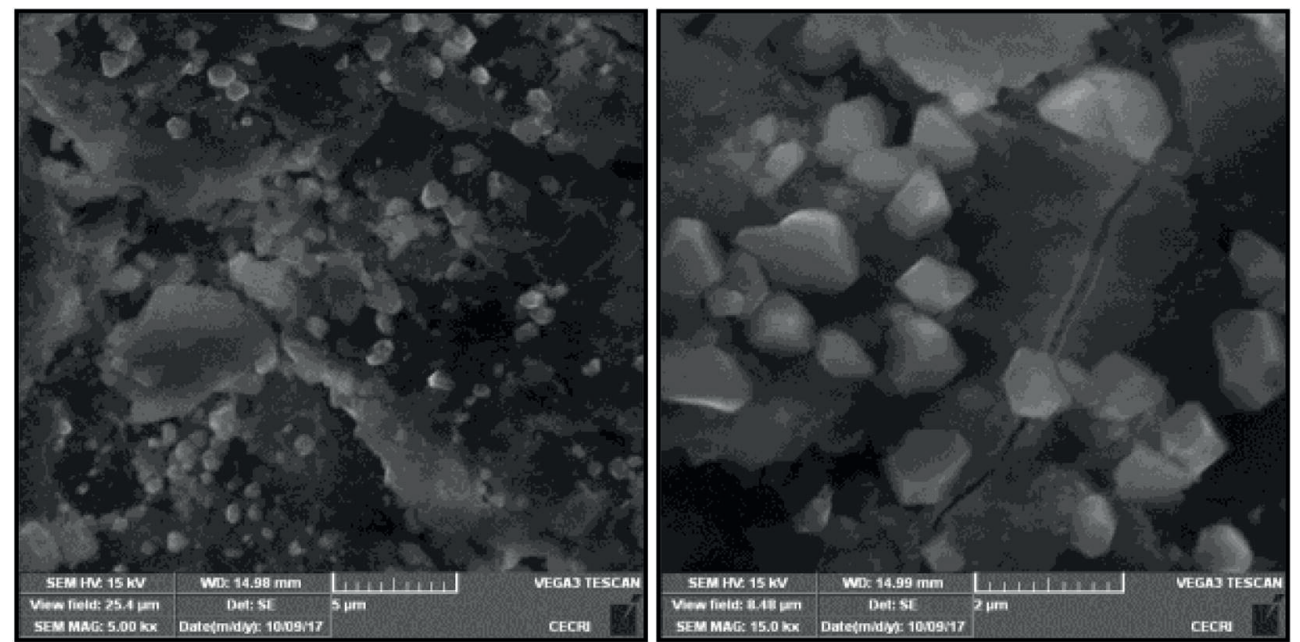

Figure 2: SEM images of gold NPs capped with Croton caudatus Geisel leaf extract (Vijaya Kumar et al. [28]).

TABLE 1: Clinical application of gold nanoparticles as drug carriers.

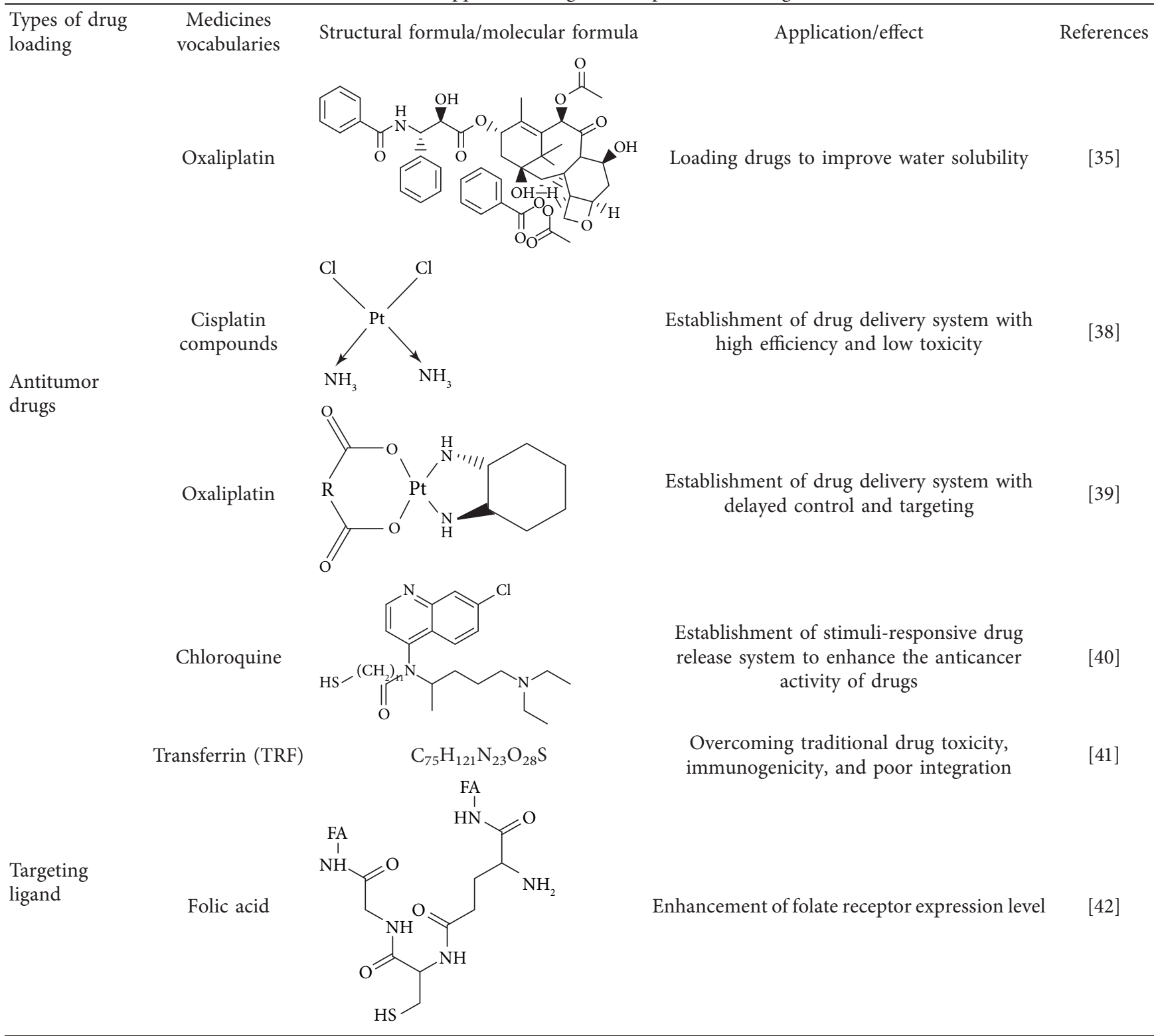


TABLE 1: Continued.

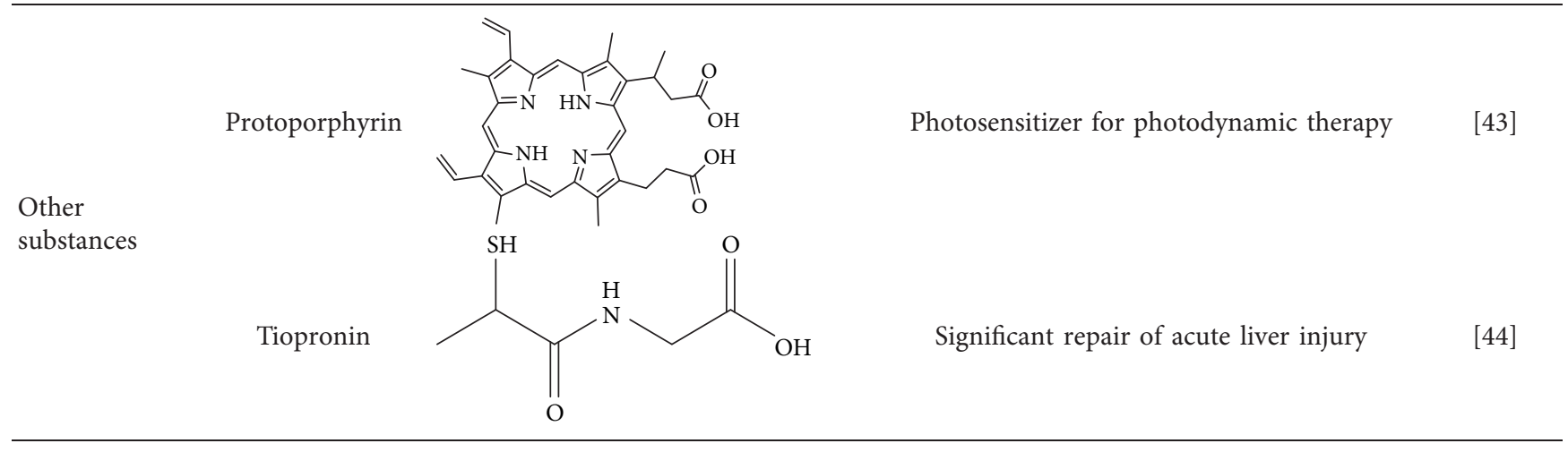

time, the limited reserves and expensive prices limit the research and utilization of gold nanoparticles. The pursuit of economic security, high efficiency, and low toxicity of gold nanomaterials is still the key point of future research [37, 47-53].

2.2. Silver Nanoparticles. Compared with gold nanoparticles, the stability of silver nanomaterials (AgNPs) is slightly poor and they will be oxidized gradually in oxygencontaining fluids [54]. However, based on the excellent characteristics of the LSPR effect and SERS effect, strong antibacterial activity, and catalytic performance of AgNPs, AgNPs have become the most widely studied inorganic nanomaterials. One of the most innovative and environmentally friendly green methods to produce silver nanoparticles is low-temperature nonequilibrium contact $[55,56]$. Skiba et al. [56] obtained SEM images (Figure 3(a)) and TEM images (Figure 3(b)) of silver nanoparticles by using low-temperature nonequilibrium contact plasma and stabilizer polysaccharide (sodium alginate). At present, common silver nanostructures include silver nanowires, silver nanocubes, and silver nanospheres [57]. Ideal optical properties can be obtained by adjusting the size, morphology, and structure of silver nanoparticles [58]. Bian et al. [58] cleverly controlled the size and morphology of silver nanoparticles by changing the volume of silver nitrate $\left(\mathrm{AgNO}_{3}\right)$ added. This kind of peptide-directed hierarchical mineralized silver nanocages prepared by biomaterial template-directed mineralization has a high tumor-killing rate of $82.7 \%$ and a photothermal conversion rate of $46.1 \%$, which belongs to the most powerful photothermal conversion of silver nanomaterials.

AgNPs have cytotoxicity, second only to mercury in antibacterial effect, and have the advantages of safety, slow release, and broad-spectrum antibacterial. The use of silver as a bactericidal material for the treatment of tumors has become a research hotspot since the 1990s. It is worth noting that the toxicity of AgNPs is not a direct effect of free $\mathrm{Ag}^{+}$but is caused by the oxidative stress of Ag nanoparticles [59]. Gurunathan et al. [60] found that AgNPs can induce oxidative stress by producing reactive oxygen species (ROS) in cells, leading to cytotoxicity, apoptosis, and necrosis of cancer cells, which is a new step in the treatment of tumors by using the antibacterial activity of AgNPs. Shi et al. [61] used doxorubicin (DOX) as a drug model, AgNPs were deposited on graphene oxide (GO) by hydrothermal reaction, and then GO@Ag was functionalized by DSPEPEG2000-NGR to prepare Go@Ag-DOX-NGR. The results show that Go@Ag-DOX-NGR has the ability of lesion targeting, photothermal ablation, and excellent X-ray imaging in the diagnosis of tumors, indicating that AgNPs have great potential in tumor diagnosis and treatment.

2.3. Platinum Nanoparticles. Since scientists first discovered the antitumor effect of cisplatin in 1969 [62], the use of metal complexes in the treatment of tumors has attracted the wide attention of medical workers. Based on the research of cisplatin, gold, silver, platinum, rhodium, palladium, and other noble metal complexes have been synthesized, which can be used in the diagnosis and therapy of cancer. Organoplatinum compounds belong to the biological alkylating agents in antitumor drugs [63], which can induce apoptosis and necrosis of tumor cells by changing the structure of target DNA and inhibiting the cell cycle [64]. Studies have shown that platinum metal nanoparticles can enhance the antitumor efficacy by regulating a variety of signal channels and activating the immune system [65-67]. Platinum nanoparticles have been widely used in clinical applications due to their excellent catalytic performance [68], imaging ability [69], excellent photothermal conversion ability, and radiosensitization ability [70]. Fu et al. [71] performed lowmagnification (Figure 4(a)) and high-magnification SEM imaging (Figure 4(b)) and TEM imaging (Figure 4(c)) on mesoporous platinum nanoparticles. The structure of platinum nanoparticles and indications in the treatment of tumors are shown in Table 2.

Cisplatin, as the first generation of platinum-based broad-spectrum antitumor drugs, has been one of the most widely used antitumor drugs since 1978. It is widely used in the clinical application treatment of prostate cancer, breast cancer, and bladder cancer [78, 79]. Cisplatin inhibits DNA replication of tumor cells, thereby hindering cancer cell division and inducing apoptosis [80]. Platinum nanoparticles combined with gemcitabine and other antitumortargeted drugs can be used as a potential drug for the treatment of ovarian clear cell carcinoma (OCCC) [81] or 


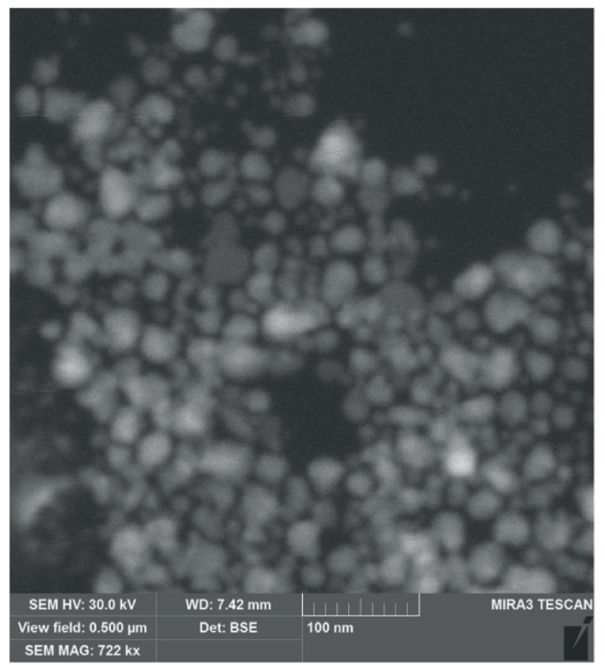

(a)

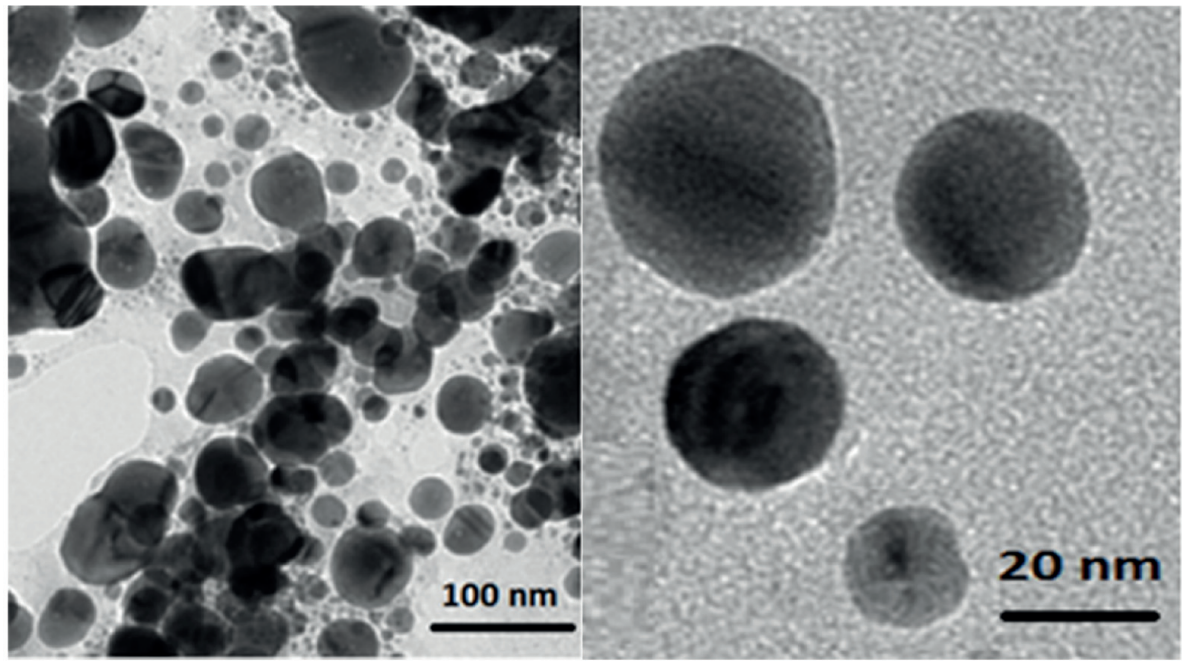

(b)

FIGURE 3: (a) SEM of silver nanoparticles obtained under plasma treatment and sodium alginate conditions $\left(\mathrm{C}_{\mathrm{AgNO}} 3.0 \mathrm{mmol} / \mathrm{l}\right)(\mathrm{Skiba}$ et al. [56]). (b) TEM of silver nanoparticles obtained under plasma treatment and sodium alginate conditions $\left(\mathrm{C}_{\mathrm{AgNO}} 3.0 \mathrm{mmol} / \mathrm{l}\right)(\mathrm{Skiba}$ et al. [56]).

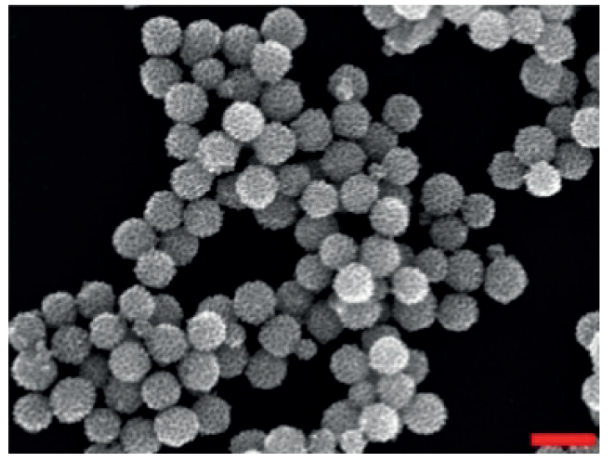

(a)

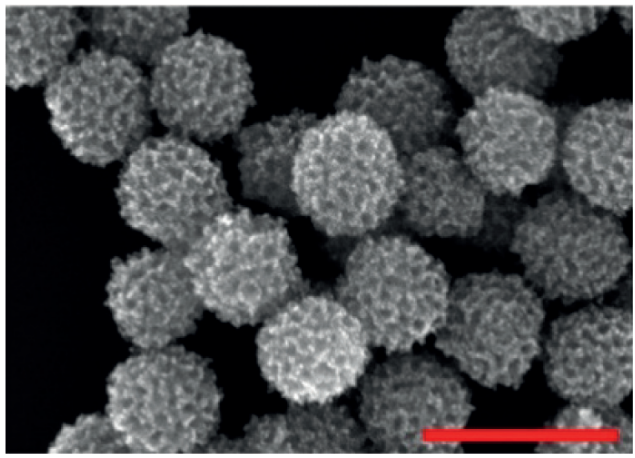

(b)

Figure 4: Continued. 


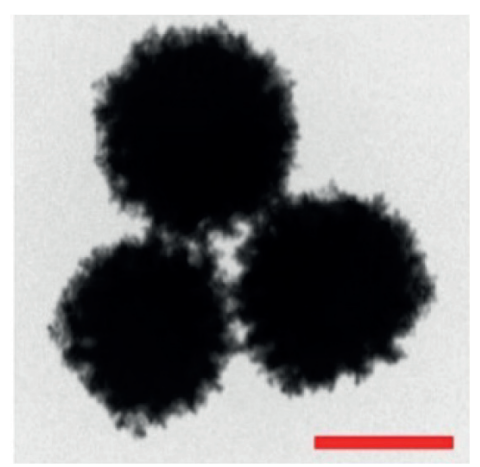

(c)

FIgURE 4: (a). Low-magnification SEM imaging of mesoporous platinum nanoparticles (Fu et al. [71]). (b). High-magnification SEM imaging of mesoporous platinum nanoparticles (Fu et al. [71]). (c). TEM imaging of mesoporous platinum nanoparticles (Fu et al. [71]).

TABLE 2: Structure of platinum nanoparticles and indications in tumor therapy.

\begin{tabular}{|c|c|c|c|c|}
\hline Types of drugs & Structural formula & Mechanism of action & Adaptive diseases & References \\
\hline $\begin{array}{l}\text { Tolfplatin } \\
\text { (cisplatin) }\end{array}$ & & $\begin{array}{c}\text { A COX-2 inhibitor that suppresses the } \\
\text { production of PEG } 2\end{array}$ & Breast cancer & {$[72]$} \\
\hline Carboplatin & & $\begin{array}{l}\text { A COX-2 inhibitor with amino-functionalized } \\
\text { polyphosphazene vesicles }\end{array}$ & Carcinoma of ovary & [73] \\
\hline Nedaplatin & & $\begin{array}{l}\text { A COX-2 inhibitor with higher plasma } \\
\text { concentrations of } 5 \text {-fluorouracil }\end{array}$ & $\begin{array}{l}\text { Esophageal squamous } \\
\text { cell carcinoma }\end{array}$ & {$[74]$} \\
\hline $\begin{array}{l}\text { Lipoxal } \\
\text { (oxaliplatin) }\end{array}$ & & $\begin{array}{c}\text { An inhibitor of DNA synthesis that prevents } \\
\text { DNA replication and transcription and causes } \\
\text { cell death }\end{array}$ & Gastrointestinal cancers & {$[75]$} \\
\hline Lobaplatin & & $\begin{array}{l}\text { Inhibit the proliferation of cancer cells and } \\
\text { promote apoptosis }\end{array}$ & Small-cell carcinoma & [76] \\
\hline Heptaplatin & & $\begin{array}{l}\text { An inhibitor of DNA synthesis that prevents } \\
\text { DNA replication and transcription }\end{array}$ & Gastric cancer & [77] \\
\hline
\end{tabular}

the treatment of advanced pancreatic cancer [82]. It not only has synergistic and immunosuppressive effects but also has no cross-resistance. However, cisplatin can only be administered by injection and has short half-life, and longterm use will produce drug resistance and serious toxicity [83].
The second-generation broad-spectrum antitumor drugs carboplatin and nedaplatin developed based on cisplatin have significantly improved their antitumor efficacy. Carboplatin is mainly used for the treatment of ovarian cancer and melanoma in the clinic. Its physicochemical properties, mechanism of action, antitumor 
spectrum, and anticancer activity are similar to those of cisplatin, and its nephrotoxicity, ototoxicity, and gastrointestinal side effects are weakened. But the administration is still intravenous administration and accompanied by serious bone marrow suppression and anemia and other adverse reactions [73]. The pharmacokinetic characteristics of nedaplatin are similar to those of carboplatin. Compared with cisplatin, its toxicological characteristics are significantly improved. Nedaplatin is mainly used for the treatment of lung cancer, esophageal cancer, and head and neck cancer in the clinic $[84,85]$.

The third-generation antitumor drugs include oxaliplatin, lobaplatin, and heptaplatin. Compared with cisplatin and carboplatin, oxaliplatin has specific targets, mechanisms of action, and drug resistance mechanisms [86]. Oxaliplatin can be used in combination with other antitumor drugs for the treatment of advanced colorectal cancer with superior efficacy and without cross-resistance. It also has an obvious inhibitory effect on drug-resistant strains of cisplatin and carboplatin [87]. The antitumor mechanism of lobaplatin is similar to that of cisplatin. Its antitumor efficiency is significantly improved, and its toxicity is similar to that of carboplatin. The main toxicity of lobaplatin is bone marrow hematopoietic inhibition, and its renal toxicity is low [76]. Heptaplatin combined with 5 -fluorouracil (5-FU) can be used for the treatment of advanced cancer, but it will produce slight and reversible proteinuria toxicity [77].

The versatility and high selectivity of platinum nanoparticles make them a promising candidate in the field of cancer therapy [88]. However, platinum compounds often cause acute kidney injury (AKI) during treatment [89]. In addition, many adverse reactions such as dose limitation, systemic toxicity, and cross-resistance limit their clinical application. Therefore, it is urgent to prepare high-efficiency, low-toxicity, safe, and stable platinum metal nanoparticles and their complexes.

2.4. Palladium Nanoparticles. Palladium nanomaterials are often used as substitutes for gold nanoparticles in the treatment of tumors because of their excellent photothermal stability, excellent catalytic activity, and significant price advantages [90]. Arsiya et al. [91] performed SEM scanning of palladium nanoparticles exposed to C. vulgaris extract, and the image is shown in Figure 5. The two-dimensional structure of ultrathin hexagonal palladium nanosheets prepared by Huang et al. [92] showed high stability under near-infrared region light. And compared with gold/silver nanostructures, palladium nanoparticles could effectively improve the photothermal conversion ability and biocompatibility. Studies have shown that the use of polymers to functionalize the surface of palladium nanoparticles can also significantly improve their biocompatibility, water dispersion, and physiological stability [90]. Bharathiraja et al. [90] modified palladium nanoparticles with chitosan (COS) and then functionalized with RGD peptide to prepare Pd@COSRGD. The experimental results showed that the functionalized palladium nanoparticles can be used as an ideal nano- inorganic material for near-infrared region laser imaging and tumor diagnosis. The surface functionalization of palladium nanoparticles can significantly improve the catalytic activity and utilization rate, and the preparation method determines the performance of palladium nanoparticles. At present, the preparation methods of palladium nanoparticles mainly include the chemical reduction method [93], biological reduction method [94], and so on. As an efficient and mature traditional method, the chemical reduction method is often combined with other preparation methods. For example, Roy et al. [95] developed a one-pot synthesis method, in which polyvinyl alcohol (PVA) was used as the steric hindrance stabilizer and citric acid was used to reduce palladium chloride to design and synthesize high dispersion and low catalytic activity, which can be widely used in biomedical fields. The mature preparation methods, significant price advantages, and excellent optical properties determine that palladium nanomaterials have great potential for research and application in the field of cancer treatment.

\section{Methods of Cancer Therapy Based on Noble Metal Nanoparticles}

With the vigorous development of nanotechnology, the research on the physicochemical properties, toxicology, and mechanism of action of noble metal nanoparticles in the treatment of tumors has become more and more thorough. Based on the LSPR effect [17], the SERS effect [18], and the MEF effect [19] of noble metal nanoparticles' surfaces, noble metal nanoparticles can be used for the early diagnosis of tumor lesion locations. Based on the efficient photothermal conversion ability of noble metal nanoparticles, tumor tissues can be thermally killed. Based on the cytotoxicity of noble metal nanoparticles, the antibacterial and antitumor effects are obvious. Based on the characteristics of noble metal nanoparticle targeting and easy modification, a targeted drug delivery system can be constructed. Noble metal nanoparticles have shown great potential development prospects in the biomedical field of tumor treatment.

3.1. Diagnosis and Treatment Integration. The study has shown that the low diagnostic rate of early cancer may be the main reason for the high mortality of cancer patients in China [2]. Because the early stage of cancer is more hidden, diagnosis is difficult, and cancer cells are easy to spread through lymphatic vessels and other channels, leading to high cancer mortality. If tumor cells are found in the early stage of cancer, it will effectively delay the survival of patients. Therefore, it is of great significance to develop a material that can assist in diagnostic imaging. Noble metal nanoparticles have an LSPR effect, which leads to obvious optical absorption in a specific wavelength region. In addition, noble metal NPs have a nonlinear optical response with electric field intensity, which presents high sensitivity and obvious imaging contrast [96]. In addition, noble metal nanoparticles are small in size, are easy to be modified by a variety of groups, and have excellent biocompatibility. Therefore, noble metal nanoparticles can be used as contrast 

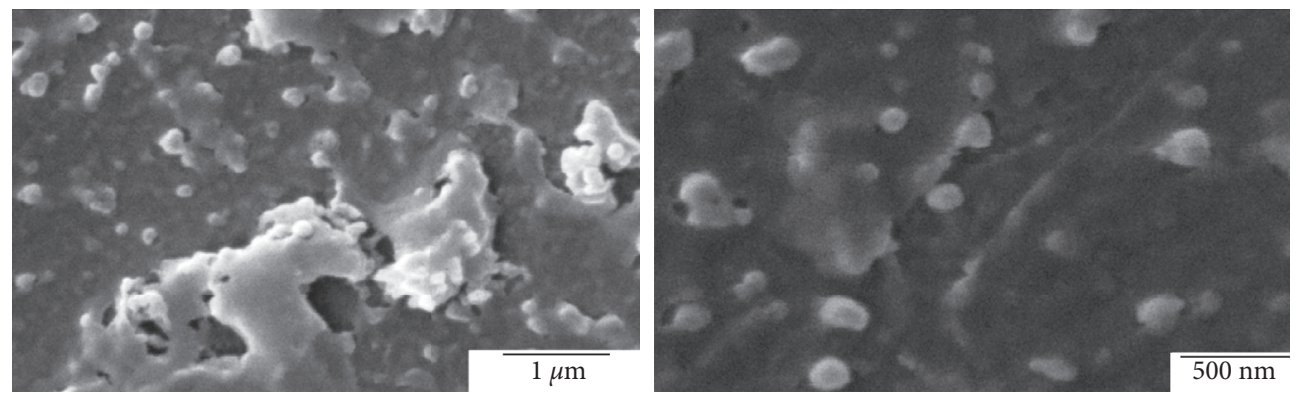

FIGURE 5: SEM micrographs of palladium NPs exposed to C. vulgaris extract (Arsiya et al. [91]).

agents for in vivo imaging for detection, labeling, in vivo imaging, and disease diagnosis of early cancer lesions [97]. Studies have shown that the binding capacity of GNPs to cancer cells is 600 times that of normal cells [98]. Compared with normal cells, tumor cells are covered with more epidermal growth factor receptors (EGFRs). Specific antibodies are modified to the surface of noble metal nanoparticles to target tumor cells for early diagnosis and imaging and to realize tumor visualization. Zhao et al. [99] prepared a novel multifunctional magnetic silver nanocomposite $\mathrm{Fe}_{3} \mathrm{O}_{4} / \mathrm{Ag}$, which can be conjugated to an epidermal growth factor receptor-specific antibody (C225) as a high-sensitivity tracer and a potential radiosensitizer. Later, the magnetic resonance phenomenon is used for diagnosis. Using the noble metal nanoparticles can realize the real-time monitoring and evaluation of drug delivery processes and treatment status [100]. At the same time, high-sensitivity and high-resolution imaging technologies such as optical imaging (OI), X-ray computed tomography (CT), and magnetic resonance imaging (MRI) can be used to realize the integration of modern medical diagnosis and treatment [101].

3.2. Hyperthermia. Due to the rapid growth of the tumor site, the lack of lymphatic vascular reflux, vascular distortion, and aggregation, and slow blood flow velocity, the heat resistance of the tumor site is poor. Studies have shown that an elevated ambient temperature in tumor tissue can induce apoptosis of tumor cells [85]. Noble metal nanoparticles are based on this principle to achieve the purpose of cancer therapy. Compared with other bands, the light in the nearinfrared region with a wavelength between $650 \mathrm{~nm}$ and $900 \mathrm{~nm}$ has a deep penetration depth of thermal damage to the tumor site. Therefore, the near-infrared region is usually preferred for in vivo tumor hyperthermia [102]. Under nearinfrared laser irradiation, noble metal nanoparticles are enriched in targeted tumor sites and convert light energy into heat energy. High temperature promotes protein inactivation and causes irreversible damage to the cell membrane, thus killing cancer cells [103]. At the same time, hyperthermia promotes the further release of anticancer drugs and realizes the combination of chemotherapy and hyperthermia. The process of hyperthermia-induced tumor cell apoptosis is shown in Figure 6. Wang et al. [32] used gold nanoparticles to modify the reductive and $\mathrm{pH}$ double-sensitive polymer vesicles wrapped with DOX and realized the combination therapy of photothermal therapy and

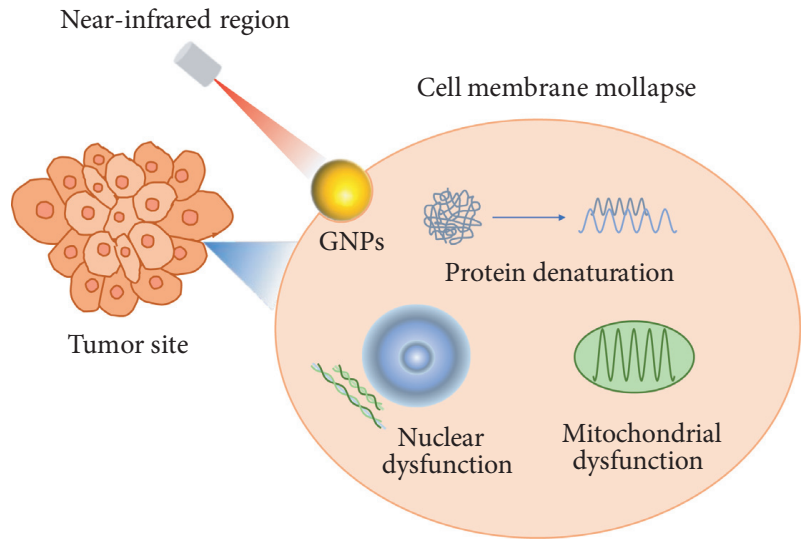

FIgURE 6: Apoptosis of tumor cells induced by hyperthermia.

chemotherapy under near-infrared laser irradiation, which greatly improved the synergistic effect and drug utilization. Nowadays, hyperthermia can be divided into photothermal therapy (PTT) [104] and photodynamic therapy (PDT) [105]. Compared with traditional chemotherapy or radiotherapy, the most prominent advantages of hyperthermia are local targeted heating and specific selection of healthy tissues, which minimizes the damage to surrounding healthy tissues [106]. Smirnov et al. [107] reported the synthesis of core-shell noble metal anisotropic nanoparticles modified with cyanine-class fluorophores and stilbene-based Raman reporters. In perspective, it may be used for optical diagnostics and therapeutic hyperthermia. In addition, hyperthermia can also activate the immune system and enhance the immune ability of the system. The advantages of safety and specificity also make hyperthermia a promising treatment for tumors in clinical applications [108].

3.3. Cytotoxicity Study. Silver nanoparticles have an excellent antibacterial effect, with cytotoxicity and heavy metal toxicity second only to mercury [109]. Since the 1990s, the use of silver as a bactericidal material for the treatment of tumors has become a research hotspot. Studies have shown that silver ions are more cytotoxic than other ions [110]. Toxicological studies in vivo and in vitro have shown that silver nanoparticles induce oxidative stress in cells to produce cytotoxicity by producing ROS. At the same time, oxidative stress can lead to mitochondrial membrane instability [111], cell apoptosis, or necrosis [112], thereby 


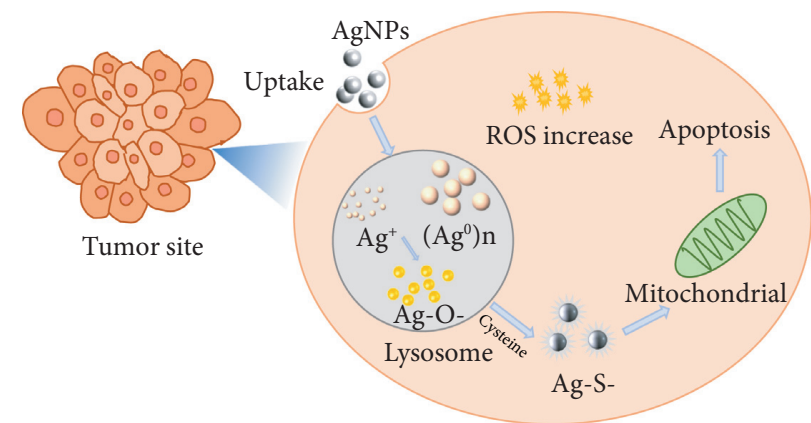

FIGURE 7: Mechanism of noble metal nanoparticles promoting apoptosis of tumor cells by cytotoxicity.

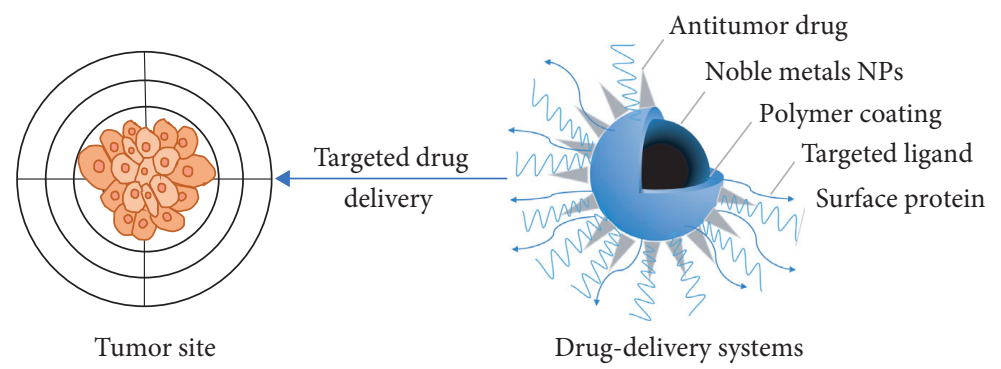

Figure 8: Brief schematic of drug delivery systems.

inhibiting tumor cells. The mechanism of noble metal nanoparticles promoting tumor cell apoptosis by cytotoxicity is shown in Figure 7. Foldbjerg et al. [113] explored the effects of silver ribosomes coated with $\mathrm{Ag}^{+}$and polyvinylpyrrolidone on the human alveolar cell line A549. In the study, it was found that the treatment of antioxidant $\mathrm{N}$-acetyl-cysteine significantly reduced the cytotoxicity of the two silver compounds, which further proved that AgNPs were the medium of ROS genetic toxicity. Studies have shown that the cytotoxicity of silver nanoparticles is closely related to their size and shape [59]. Compared with 50-100 nm-diameter nanoparticles, silver nanoparticles with the smallest diameter of $10-20 \mathrm{~nm}$ have the strongest cytotoxicity. Silver nanowires $(1.5-25 \mu \mathrm{m}$ in length, $100-160 \mathrm{~nm}$ in diameter) are more toxic than spherical nanowires (30 $\mathrm{nm}$ in diameter) [59].

In addition, cisplatin is also a representative drug for cytotoxicity research. Cisplatin selectively binds to tumor cell DNA, blocks cell cycle, and inhibits DNA replication and transcription of tumor cells, thereby exerting cytotoxicity [114]. Shiny et al. [115] found that platinum nanoparticles can upregulate the expression of apoptotic markers and downregulate the expression of antiapoptotic genes to promote apoptosis and necrosis of tumor cells. Studies have shown that platinum nanoparticles have a good therapeutic effect on tumors.

3.4. Drug Delivery System. Antitumor drug delivery systems are constructed by physical embedding, covalent binding, and electrostatic interaction of antitumor drugs and noble metal nanoparticles [116]. Significantly, noble metal nanocarriers are based on the concept of targeting drug delivery systems (TDDSs) [117] and composed of noble metal-organic frameworks (NMOFs) with nanoparticle sizes of $\mathrm{nm}$. As shown in Figure 8, gold nanoparticles, which are widely used in clinical practice, can be loaded with antitumor drugs [35], targeting ligands [42], and other drugs [43] by functional modification [33] or chemical bond binding [35, 36]. Ding et al. [35] designed and synthesized thiol-terminated PEGylated paclitaxel derivatives by the chemical synthesis method and conjugated with gold nanoparticles, which significantly improved drug loading, drug cycle time, and tumor cell killing efficiency. Noble metal nanoparticles not only have excellent biocompatibility, large specific surface area, liquid fluidity, and strong magnetic properties of solid [41] but also are sensitive to small changes in the external environment ( $\mathrm{pH}$, temperature, light, etc.) [118]. Therefore, a photo-responsive drug delivery system for noble metal nanoparticles can be established through remote spatiotemporal control. You et al. [119] designed and synthesized multifunctional doxorubicin (DOX)-loaded hollow gold nanoparticles (DOX@HAuNPs). Under the condition of near-infrared laser irradiation, GNPs were used as carriers to achieve targeted transport, accelerate the release of drugs, realize the combination of hyperthermia and chemotherapy, increase the anticancer activity of drugs, and reduce organ toxicity. Based on enhanced permeability and retention (EPR) [120], after the drug delivery system is phagocytized by macrophages, it can achieve passive targeted delivery [121] or achieve targeted delivery based on active targeted delivery [122] and environmental-responsive targeted delivery $[118,123-125]$ to achieve high efficiency and low toxicity, controlled release, and targeted delivery. However, the current research on antitumor drug nanocarriers mostly focuses on the basic theory, and the synthesis of complex 
nanocarrier drug technology is not yet mature. The low proportion of drugs that can be used in clinical experiments and practical applications, poor penetration ability, and low drug utilization limit the wide application of nano-antitumor drug carriers $[126,127]$.

\section{Conclusion and Prospect}

At present, cancer treatment still faces many challenges. But with the development of nanotechnology, the application of noble metal nanoparticles is expected to become an excellent weapon for the treatment of tumors. Noble metal nanoparticles have shown great potential in the biomedical field. The application of noble metal nanoparticles effectively overcomes the shortcomings of traditional tumor treatment methods and truly creates a new, safe, and minimally invasive tumor treatment system. In the diagnosis of cancer, based on the unique optical properties and excellent biocompatibility, researchers use advanced imaging technology to make noble metal nanoparticles as a contrast agent for self-imaging in vivo, which can significantly improve the signal intensity and enhance the contrast between normal tissues and tumor sites, to achieve the integration of diagnosis and treatment [97]. In the treatment of cancer, noble metal nanoparticles have SERS optical activity, which can efficiently convert light energy into heat energy, to carry out PTT or PDT on tumor sites [46]. In addition, noble metal nanoparticles can produce ROS to induce oxidative stress in cells to produce cytotoxicity and promote apoptosis and necrosis of tumor cells, thereby inhibiting the growth and reproduction of tumor cells [128]. At the same time, noble metal nanoparticles can also load a variety of antitumor drugs, respond to small changes in the external environment, and establish targeted drug delivery systems by passive and active transport, greatly improving the bioavailability of drugs [129]. However, noble metal nanoparticles also face many challenges in the application of clinical treatment. Noble metal nanoparticles are closely related to the health and life of patients. Therefore, great attention should be paid to their safety and toxicity. According to its biodynamics (absorption, distribution, metabolism, excretion) to evaluate and discover, noble metal nanoparticle drugs have fewer biocompatibility and biosafety issues [130]. The toxicity of nanoparticles may be different depending on the specific nanoproperties from which their reactivity, retention time, and distribution in the human body derive [131]. It is relatively difficult to determine the toxicity of precious metal nanoparticles based on the current toxicological studies. However, experimental animal trials have advantages, with one of the important ones being the assessment of the kinetics of nanoparticles through absorption, distribution, metabolism, and excretion (ADME) [132]. Li et al. [49] believed that the toxicity of noble metal nanoparticles should be different from the toxicity of antitumor drugs loaded on the surface of noble metal nanoparticles. Moreover, the oxidation state of noble metal nanoparticles should be also paid attention. In addition, due to the differences in the progress of theory and practice, and the difficulty in synthesizing complex nanomedicines, it is still necessary to further study the preparation, in vivo behavior, safety, and drug utilization of noble metal nanoparticles. The in-depth study on the mechanism of action, metabolism in vivo, pharmacokinetics, and toxicological principles of noble metal nanoparticles can promote the joint and synergistic effect of various mechanisms of noble metal nanoparticles, create new design ideas for the realization of high efficiency and low toxicity of noble metal nanocomposites, and lay a solid foundation for the exploration and development of new resources of noble metal nanoparticles.

\section{Data Availability}

All data supporting this work are included within the paper.

\section{Conflicts of Interest}

The authors declare that they have no conflicts of interest.

\section{References}

[1] K. K. Jain, “An overview of drug delivery systems," Drug Delivery Systems, vol. 2059, pp. 1-54, 2020.

[2] R.-M. Feng, Y.-N. Zong, S.-M. Cao, and R.-H. Xu, "Current cancer situation in China: good or bad news from the 2018 Global Cancer Statistics?" Cancer Communications, vol. 39, no. 1, p. 22, 2019.

[3] H. Furue, "[Chemotherapy cancer treatment during the past sixty years]. Gan to kagaku ryoho," Cancer \& Chemotherapy, vol. 30, no. 10, pp. 1404-1411, 2003.

[4] A. M. Evens, B. D. Jovanovic, Y.-C. Su et al., "Rituximabassociated hepatitis B virus (HBV) reactivation in lymphoproliferative diseases: meta-analysis and examination of FDA safety reports," Annals of Oncology, vol. 22, no. 5, pp. 1170-1180, 2011.

[5] M. Rizwanullah, M. Alam, Harshita, S. R. Mir, M. M. A. Rizvi, and S. Amin, "Polymer-Lipid hybrid nanoparticles: a next-generation nanocarrier for targeted treatment of solid tumors," Current Pharmaceutical Design, vol. 26, no. 11, pp. 1206-1215, 2020.

[6] S.-S. Qi, J.-H. Sun, H.-H. Yu, and S.-Q. Yu, "Co-delivery nanoparticles of anti-cancer drugs for improving chemotherapy efficacy," Drug Delivery, vol. 24, no. 1, pp. 1909-1926, 2017.

[7] R. M. Kannan, E. Nance, S. Kannan, and D. A. Tomalia, "Emerging concepts in dendrimer-based nanomedicine: from design principles to clinical applications," Journal of Internal Medicine, vol. 276, no. 6, pp. 579-617, 2014.

[8] J. Guo, H. Zeng, and Y. Chen, "Emerging nano drug delivery systems targeting cancer-associated fibroblasts for improved antitumor effect and tumor drug penetration," Molecular Pharmaceutics, vol. 17, no. 4, pp. 1028-1048, 2020.

[9] K. McNamara and S. A. M. Tofail, "Nanoparticles in biomedical applications," Advances in Physics: X, vol. 2, no. 1, pp. 54-88, 2017.

[10] B. Klębowski, J. Depciuch, M. Parlińska-Wojtan, and J. Baran, "Applications of noble metal-based nanoparticles in medicine," International Journal of Molecular Sciences, vol. 19, no. 12, 2018. 
[11] Z. Ma, Y. Jiang, H. Xiao et al., "Sol-gel preparation of Agsilica nanocomposite with high electrical conductivity," Applied Surface Science, vol. 436, pp. 732-738, 2018.

[12] F. Mafuné, "Formation and size control of silver nanoparticles by laser ablation in aqueous solution," The Journal of Physical Chemistry B, vol. 104, no. 39, pp. 9111-9117, 2000.

[13] H. Wender, L. F. de Oliveira, A. F. Feil et al., "Synthesis of gold nanoparticles in a biocompatible fluid from sputtering deposition onto castor oil," Chemical Communications, vol. 46, no. 37, pp. 7019-7021, 2010.

[14] D. J. Maxwell, S. R. Emory, and S. Nie, "Nanostructured thinfilm materials with surface-enhanced optical properties," Chemistry of Materials, vol. 13, no. 3, pp. 1082-1088, 2001.

[15] C. Z. Jiang and X. J. Fan, "In-situ TEM observation of silver nanocrystals in an Ag-implanted $\mathrm{SiO} 2$ film," Surface and Coatings Technology, vol. 131, no. 1, pp. 330-333, 2000.

[16] T. S. Rodrigues, A. G. M. da Silva, and P. H. C. Camargo, "Nanocatalysis by noble metal nanoparticles: controlled synthesis for the optimization and understanding of activities," Journal of Materials Chemistry A, vol. 7, no. 11, pp. 5857-5874, 2019.

[17] M. P. Melancon, M. Zhou, and C. Li, "Cancer theranostics with near-infrared light-activatable multimodal nanoparticles," Accounts of Chemical Research, vol. 44, no. 10, pp. 947-956, 2011.

[18] W. Xie and S. Schlücker, "Surface-enhanced Raman spectroscopic detection of molecular chemo-and plasmo-catalysis on noble metal nanoparticles," Chemical Communications, vol. 54, no. 19, pp. 2326-2336, 2018.

[19] S. Pawar, A. Bhattacharya, and A. Nag, "Metal-enhanced fluorescence study in aqueous medium by coupling gold nanoparticles and fluorophores using a bilayer vesicle platform," ACS Omega, vol. 4, no. 3, pp. 5983-5990, 2019.

[20] W. Ye, J. Yan, Q. Ye, and F. Zhou, "Template-free and direct electrochemical deposition of hierarchical dendritic gold microstructures: growth and their multiple applications," The Journal of Physical Chemistry C, vol. 114, no. 37, pp. 15617-15624, 2010.

[21] M. Brust, M. Walker, D. Bethell, D. J. Schiffrin, and R. Whyman, "Synthesis of thiol-derivatised gold nanoparticles in a two-phase Liquid-Liquid system," J. Chem. Soc., Chem. Commun.vol. 7, no. 7, pp. 801-802, 1994.

[22] N. R. Jana, L. Gearheart, and C. J. Murphy, "Seed-mediated growth approach for shape-controlled synthesis of spheroidal and rod-like gold nanoparticles using a surfactant template," Advanced Materials, vol. 13, no. 18, pp. 1389-1393, 2001.

[23] B. Nikoobakht and M. A. El-Sayed, "Preparation and growth mechanism of gold nanorods (NRs) using seed-mediated growth method," CHEMISTRY OF MATERIALS, vol. 15, no. 10, pp. 1957-1962, 2003.

[24] G. Southam and T. J. Beveridge, "The occurrence of sulfur and phosphorus within bacterially derived crystalline and pseudocrystalline octahedral gold formed in vitro," Geochimica et Cosmochimica Acta, vol. 60, no. 22, pp. 43694376, 1996.

[25] B. Seo, K. Lim, S. S. Kim et al., "Small gold nanorods-loaded hybrid albumin nanoparticles with high photothermal efficacy for tumor ablation," Colloids and Surfaces B: Biointerfaces, vol. 179, pp. 340-351, 2019.

[26] T. T. V. Phan, V. T. Nguyen, S.-H. Ahn, and J. Oh, "Chitosan-mediated facile green synthesis of size-controllable gold nanostars for effective photothermal therapy and photoacoustic imaging," European Polymer Journal, vol. 118, pp. 492-501, 2019.

[27] P. Manivasagan, G. Hoang, S. Mondal et al., "Thiol chitosanwrapped gold nanoshells for near-infrared laser-induced photothermal destruction of antibiotic-resistant bacteria," Carbohydrate Polymers, vol. 225, 2019.

[28] P. Vijaya Kumar, S. Mary Jelastin Kala, and K. S. Prakash, "Green synthesis of gold nanoparticles using Croton Caudatus Geisel leaf extract and their biological studies," $\mathrm{Ma}$ terials Letters, vol. 236, pp. 19-22, 2019.

[29] Y.-J. Gu, J. Cheng, C. W.-Y. Man, W.-T. Wong, and S. H. Cheng, "Gold-doxorubicin nanoconjugates for overcoming multidrug resistance," Nanomedicine: Nanotechnology, Biology and Medicine, vol. 8, no. 2, pp. 204-211, 2012.

[30] P. Mukherjee, R. Bhattacharya, P. Wang et al., "Antiangiogenic properties of gold nanoparticles," Clinical Cancer Research, vol. 11, no. 9, pp. 3530-3534, 2005.

[31] W. Huang, Y. Xing, L. Zhu, J. Zhuo, and M. Cai, "Sorafenib derivatives-functionalized gold nanoparticles confer protection against tumor angiogenesis and proliferation via suppression of EGFR and VEGFR-2," Experimental Cell Research, vol. 406, no. 1, Article ID 112633, 2021.

[32] L. Wang, Y. Yuan, S. Lin et al., "Photothermo-chemotherapy of cancer employing drug leakage-free gold nanoshells," Biomaterials, vol. 78, pp. 40-49, 2016.

[33] F. Gao, M. Sun, L. Xu, L. Liu, H. Kuang, and C. Xu, "Biocompatible cup-shaped nanocrystal with ultrahigh photothermal efficiency as tumor therapeutic agent," Advanced Functional Materials, vol. 27, no. 24, Article ID 1700605, 2017.

[34] S. Jibin, "Sequential drug release and enhanced photothermal and photoacoustic effect of hybrid reduced graphene oxideloaded ultrasmall gold nanorod vesicles for cancer therapy," ACS Nano, vol. 9, no. 9, 2015.

[35] Y. Ding, Y.-Y. Zhou, H. Chen et al., "The performance of thiol-terminated PEG-paclitaxel-conjugated gold nanoparticles," Biomaterials, vol. 34, no. 38, pp. 10217-10227, 2013.

[36] S. T. Kim, A. Chompoosor, Y.-C. Yeh, S. S. Agasti, D. J. Solfiell, and V. M. Rotello, "Dendronized gold nanoparticles for siRNA delivery," Small, vol. 8, no. 21, pp. 3253-3256, 2012.

[37] X. Sun, X. Huang, X. Yan et al., "Chelator-free 64Cu-integrated gold nanomaterials for positron emission tomography imaging guided photothermal cancer therapy," ACS Nano, vol. 8, no. 8, pp. 8438-8446, 2014.

[38] S. Sánchez-Paradinas, M. Pérez-Andrés, M. J. AlmendralParra et al., "Enhanced cytotoxic activity of bile acid cisplatin derivatives by conjugation with gold nanoparticles," J Inorg Biochem, vol. 131, pp. 8-11, 2014.

[39] S. D. Brown, P. Nativo, J.-A. Smith et al., "Gold nanoparticles for the improved anticancer drug delivery of the active component of oxaliplatin," Journal of the American Chemical Society, vol. 132, no. 13, pp. 4678-4684, 2010.

[40] P. Joshi, S. Chakraborti, J. E. Ramirez-Vick et al., "The anticancer activity of chloroquine-gold nanoparticles against MCF-7 breast cancer cells," Colloids and Surfaces B: Biointerfaces, vol. 95, pp. 195-200, 2012.

[41] S.-J. Choi, J.-M. Oh, and J.-H. Choy, "Biocompatible nanoparticles intercalated with anticancer drug for target delivery: pharmacokinetic and biodistribution study," Journal of Nanoscience and Nanotechnology, vol. 10, no. 4, pp. 2913-2916, 2010. 
[42] Z. Zhang, J. Jia, Y. Lai, Y. Ma, J. Weng, and L. Sun, "Conjugating folic acid to gold nanoparticles through glutathione for targeting and detecting cancer cells," Bioorganic \& Medicinal Chemistry, vol. 18, no. 15, pp. 5528-5534, 2010.

[43] H. Eshghi, A. Sazgarnia, M. Rahimizadeh, N. Attaran, M. Bakavoli, and S. Soudmand, "Protoporphyrin IX-gold nanoparticle conjugates as an efficient photosensitizer in cervical cancer therapy," Photodiagnosis and Photodynamic Therapy, vol. 10, no. 3, pp. 304-312, 2013.

[44] Q. Y. Bao, D. D. Geng, J. W. Xue et al., "Glutathione-mediated drug release from Tiopronin-conjugated gold nanoparticles for acute liver injury therapy," International Journal of Pharmaceutics, vol. 446, no. 1-2, pp. 112-118, 2013.

[45] W. N. Rahman, M. Geso, N. Yagi, S. A. Abdul Aziz, S. Corde, and N. Annabell, "Optimal energy for cell radiosensitivity enhancement by gold nanoparticles using synchrotron-based monoenergetic photon beams," International Journal of Nanomedicine, vol. 9, pp. 2459-2467, 2014.

[46] B. Van de Broek, N. Devoogdt, A. D'Hollander et al., "Specific cell targeting with nanobody conjugated branched gold nanoparticles for photothermal therapy," ACS Nano, vol. 5, no. 6, pp. 4319-4328, 2011.

[47] J. Li, J. Liu, and C. Chen, "Remote control and modulation of cellular events by plasmonic gold nanoparticles: implications and opportunities for biomedical applications," ACS Nano, vol. 11, no. 3, pp. 2403-2409, 2017.

[48] W. Zhou, X. Gao, D. Liu, and X. Chen, "Gold nanoparticles for in vitro diagnostics," Chemical Reviews, vol. 115, no. 19, pp. 10575-10636, 2015.

[49] N. Li, P. Zhao, and D. Astruc, "Anisotropic gold nanoparticles: synthesis, properties, applications, and toxicity," Angewandte Chemie International Edition, vol. 53, no. 7, pp. 1756-1789, 2014.

[50] J. Song, X. Yang, O. Jacobson et al., "Sequential drug release and enhanced photothermal and photoacoustic effect of hybrid reduced graphene oxide-loaded ultrasmall gold nanorod vesicles for cancer therapy," ACS Nano, vol. 9, no. 9, pp. 9199-9209, 2015.

[51] R. Cheheltani, R. M. Ezzibdeh, P. Chhour et al., "Tunable, biodegradable gold nanoparticles as contrast agents for computed tomography and photoacoustic imaging," Biomaterials, vol. 102, pp. 87-97, 2016.

[52] X. Ge, Z.-M. Song, L. Sun et al., "Lanthanide (Gd(3+) and $\mathrm{Yb}(3+))$ functionalized gold nanoparticles for in vivo imaging and therapy," Biomaterials, vol. 108, pp. 35-43, 2016.

[53] Y. Chang, L. He, Z. Li et al., "Designing core-shell gold and selenium nanocomposites for cancer radiochemotherapy," ACS Nano, vol. 11, no. 5, pp. 4848-4858, 2017.

[54] L. Wang, T. Zhang, P. Li et al., "Use of synchrotron radiation-analytical techniques to reveal chemical origin of silver-nanoparticle cytotoxicity," ACS Nano, vol. 9, no. 6, pp. 6532-6547, 2015.

[55] G. Saito and T. Akiyama, "Nanomaterial synthesis using plasma generation in liquid," J. Nanomaterials, vol. 16, no. 1, Article ID 299, 2016.

[56] M. I. Skiba, V. I. Vorobyova, A. Pivovarov, and N. P. Makarshenko, "Green synthesis of silver nanoparticles in the presence of polysaccharide: optimization and characterization," Journal of Nanomaterials, vol. 2020, Article ID 3051308, 2020.

[57] G. Lin, W. Dong, C. Wanga, and W. Lu, "Mechanistic study on galvanic replacement reaction and synthesis of $\mathrm{Ag}-\mathrm{Au}$ alloy nanoboxes with good surface- enhanced Raman scattering activity to detect melamine," Sensors \& Actuators: B. Chemical, vol. 263, 2018.

[58] K. Bian, X. Zhang, K. Liu et al., "Peptide-directed hierarchical mineralized silver nanocages for anti-tumor photothermal therapy," ACS Sustainable Chemistry \& Engineering, vol. 6, no. 6, pp. 7574-7588, 2018.

[59] S. J. Soenen, W. J. Parak, J. Rejman, and B. Manshian, "(Intra)Cellular stability of inorganic nanoparticles: effects on cytotoxicity, particle functionality, and biomedical applications," Chemical Reviews, vol. 115, no. 5, pp. 2109-2135, 2015.

[60] S. Gurunathan, J. W. Han, V. Eppakayala, M. Jeyaraj, and J. H. Kim, "Cytotoxicity of biologically synthesized silver nanoparticles in MDA-MB-231 human breast cancer cells," Biomed Research International, vol. 2013, Article ID 535796, 2013.

[61] J. Shi, L. Wang, J. Zhang et al., "A tumor-targeting nearinfrared laser-triggered drug delivery system based on GO@ Ag nanoparticles for chemo-photothermal therapy and X-ray imaging," Biomaterials, vol. 35, no. 22, pp. 5847-5861, 2014.

[62] B. Rosenberg, L. Vancamp, J. E. Trosko, and V. H. Mansour, "Platinum compounds: a new class of potent antitumour agents," Nature, vol. 222, no. 5191, pp. 385-386, 1969.

[63] N. Kondo, A. Takahashi, K. Ono, and T. Ohnishi, "DNA damage induced by alkylating agents and repair pathways," Journal of Nucleic Acids, vol. 2010, Article ID 543531, 2010.

[64] E. B. Douple, "Cis-diamminedichloroplatinum(II): effects of a representative metal coordination complex on mammalian cells," Pharmacology \& Therapeutics, vol. 25, no. 3, pp. 297-326, 1984.

[65] N.-R. Kim and Y.-J. Kim, "Oxaliplatin regulates myeloidderived suppressor cell-mediated immunosuppression via downregulation of nuclear factor- $\kappa \mathrm{B}$ signaling," Cancer Medicine, vol. 8, no. 1, pp. 276-288, 2019.

[66] D. Y. Q. Wong, C. H. F. Yeo, and W. H. Ang, "Immunochemotherapeutic platinum(IV) prodrugs of cisplatin as multimodal anticancer agents," Angewandte Chemie International Edition, vol. 53, no. 26, pp. 6752-6756, 2014.

[67] K. M. Felsenstein and D. Theodorescu, "Precision medicine for urothelial bladder cancer: update on tumour genomics and immunotherapy," Nature Reviews Urology, vol. 15, no. 2, pp. 92-111, 2018.

[68] H. Wei and E. Wang, "Nanomaterials with enzyme-like characteristics (nanozymes): next-generation artificial enzymes," Chemical Society Reviews, vol. 42, no. 14, pp. 6060-6093, 2013.

[69] Z. Medř́ková, V. Novohradsky, J. Zajac et al., "Enhancing tumor cell response to chemotherapy through the targeted delivery of platinum drugs mediated by highly stable, multifunctional carboxymethylcellulose-coated magnetic nanoparticles," Chemistry (Weinheim an der Bergstrasse, Germany), vol. 22, no. 28, pp. 9750-9759, 2016.

[70] J. Wei, J. Li, D. Sun et al., “A novel theranostic nanoplatform based on Pd@Pt-PEG-Ce6 for enhanced photodynamic therapy by modulating tumor hypoxia microenvironment," Advanced Functional Materials, vol. 28, no. 17, Article ID 1706310, 2018.

[71] B. Fu, M. Dang, J. Tao, Y. Li, and Y. Tang, "Mesoporous platinum nanoparticle-based nanoplatforms for combined chemo-photothermal breast cancer therapy," Journal of Colloid and Interface Science, vol. 570, pp. 197-204, 2020.

[72] X. Lei, C.-Xi Yang, Di Zhao et al., "A carrier-free anti-inflammatory platinum (II) self-delivered nanoprodrug for 
enhanced breast cancer therapy," Journal of Controlled Release, vol. 331, 2021.

[73] X. Zhu, Y. Peng, and L. Qiu, "Amino-functionalized nanovesicles for enhanced anticancer efficacy and reduced myelotoxicity of carboplatin," Colloids and Surfaces B: Biointerfaces, vol. 157, pp. 56-64, 2017.

[74] H. Zhu, X. Ge, Y. Lu et al., "Nedaplatin-based chemotherapy regimens combined with concurrent radiotherapy as firstline treatment for stage II-III esophageal squamous cell carcinoma," Oncology Letters, vol. 17, no. 1, pp. 594-602, 2019.

[75] G. P. Stathopoulos, T. Boulikas, A. Kourvetaris, and J. Stathopoulos, "Liposomal oxaliplatin in the treatment of advanced cancer: a phase I study," Anticancer Research, vol. 26, no. 2b, pp. 1489-1493, 2006.

[76] N. J. Wheate, S. Walker, G. E. Craig, and R. Oun, "The status of platinum anticancer drugs in the clinic and in clinical trials," Dalton Transactions, vol. 39, no. 35, pp. 8113-8127, 2010.

[77] Y. J. Min, S.-J. Bang, J. W. Shin et al., "Combination chemotherapy with 5-fluorouracil and heptaplatin as first-line treatment in patients with advanced gastric cancer," Journal of Korean Medical Science, vol. 19, no. 3, pp. 369-373, 2004.

[78] D. G. Moon, S. E. Lee, M. M. Oh et al., "NVP-BEZ235, a dual $\mathrm{PI} 3 \mathrm{~K} / \mathrm{mTOR}$ inhibitor synergistically potentiates the antitumor effects of cisplatin in bladder cancer cells," International Journal of Oncology, vol. 45, no. 3, pp. 1027-1035, 2014.

[79] P. Ru, R. Steele, E. C. Hsueh, and R. B. Ray, "Anti-miR-203 upregulates SOCS3 expression in breast cancer cells and enhances cisplatin chemosensitivity," Genes \& Cancer, vol. 2, no. 7, pp. 720-727, 2011.

[80] G. L. Cohen, W. R. Bauer, J. K. Barton, and S. J. Lippard, "Binding of cis- and trans-dichlorodiammineplatinum (II) to DNA: evidence for unwinding and shortening of the double helix," Science, vol. 203, no. 4384, pp. 1014-1016, 1979.

[81] F. Simpkins, J. Belinson, and P. Rose, "Avoiding bevacizumab related gastrointestinal toxicity for recurrent ovarian cancer by careful patient screening," Gynecologic Oncology, vol. 107, no. 1, pp. 118-123, 2007.

[82] G. Stathopoulos, T. Boulikas, M. Vougiouka, S. Rigatos, and J. Stathopoulos, "Liposomal cisplatin combined with gemcitabine in pretreated advanced pancreatic cancer patients: a phase I-II study," Oncology Reports, vol. 15, no. 5, pp. 1201-1204, 2006.

[83] A. Abu-Surrah and M. Kettunen, "Platinum group antitumor chemistry: design and development of new anticancer drugs complementary to cisplatin," Current Medicinal Chemistry, vol. 13, no. 11, pp. 1337-1357, 2006.

[84] A. Kuwahara, M. Yamamori, K. Nishiguchi et al., "Replacement of cisplatin with nedaplatin in a definitive 5fluorouracil/cisplatin-based chemoradiotherapy in Japanese patients with esophageal squamous cell carcinoma," International Journal of Medical Sciences, vol. 6, no. 6, pp. 305311, 2009.

[85] H. Okuda, M. Ohnishi, H. Takahashi, C. Takagi, N. Takada, and T. Ohashi, "Long-term efficacy and toxicity of concurrent chemoradiotherapy with nedaplatin and S-1 for head and neck squamous cell carcinoma," Auris Nasus Larynx, vol. 46, no. 6, pp. 882-888, 2019.

[86] E. Raymond, S. G. Chaney, A. Taamma, and E. Cvitkovic, "Oxaliplatin: a review of preclinical and clinical studies," Annals of Oncology, vol. 9, no. 10, pp. 1053-1071, 1998.
[87] A. de Gramont, A. Figer, M. Seymour et al., "Leucovorin and fluorouracil with or without oxaliplatin as first-line treatment in advanced colorectal cancer," Journal of Clinical Oncology, vol. 18, no. 16, pp. 2938-2947, 2000.

[88] J. Fan, J.-J. Yin, B. Ning et al., "Direct evidence for catalase and peroxidase activities of ferritin-platinum nanoparticles," Biomaterials, vol. 32, no. 6, pp. 1611-1618, 2011.

[89] D. A. Foxwell, S. Pradhan, S. Zouwail, T. H. Rainer, and A. O. Phillips, "Epidemiology of emergency department acute kidney injury," Nephrology, vol. 25, no. 6, pp. 457-466, 2020.

[90] S. Bharathiraja, N. Q. Bui, P. Manivasagan et al., "Multimodal tumor-homing chitosan oligosaccharide-coated biocompatible palladium nanoparticles for photo-based imaging and therapy," Scientific Reports, vol. 8, no. 1, p. 500, 2018.

[91] F. Arsiya, M. H. Sayadi, and S. Sobhani, "Green synthesis of palladium nanoparticles using Chlorella vulgaris," Materials Letters, vol. 186, pp. 113-115, 2017.

[92] X. Huang, S. Tang, X. Mu et al., "Freestanding palladium nanosheets with plasmonic and catalytic properties," Nature Nanotechnology, vol. 6, no. 1, pp. 28-32, 2011.

[93] G. F. Alvarez, M. Mamlouk, S. M. Senthil Kumar, and K. Scott, "Preparation and characterisation of carbon-supported palladium nanoparticles for oxygen reduction in low temperature PEM fuel cells," Journal Of Applied Electrochemistry, vol. 41, no. 8, pp. 925-937, 2011.

[94] S. Momeni and I. Nabipour, "A simple green synthesis of palladium nanoparticles with sargassum alga and their electrocatalytic activities towards hydrogen peroxide," Applied Biochemistry and Biotechnology, vol. 176, no. 7, pp. 1937-1949, 2015.

[95] P. S. Roy, J. Bagchi, and S. K. Bhattacharya, "Size-controlled synthesis and characterization of polyvinyl alcohol coated palladium nanoparticles," Transition Metal Chemistry, vol. 34, no. 4, 2009.

[96] Y. Ma, J. Huang, S. Song, H. Chen, and Z. Zhang, "Cancertargeted nanotheranostics: recent advances and perspectives," Small, vol. 12, no. 36, pp. 4936-4954, 2016.

[97] J. Wang, G. Zhang, Q. Li et al., "In vivo self-bio-imaging of tumors through in situ biosynthesized fluorescent gold nanoclusters," Scientific Reports, vol. 3, no. 1, p. 1157, 2013.

[98] P. K. Jain, I. H. El-Sayed, and M. A. El-Sayed, "Au nanopartices target cancer (vol 2, pg 18, 2007)," Nano Today, vol. 2, no. 2, p. 16, 2007.

[99] D. Zhao, X. Sun, J. Tong et al., "A novel multifunctional nanocomposite $\mathrm{C} 225$-conjugated $\mathrm{Fe} 3 \mathrm{O} 4 / \mathrm{Ag}$ enhances the sensitivity of nasopharyngeal carcinoma cells to radiotherapy," Acta Biochimica et Biophysica Sinica, vol. 44, no. 8, pp. $678-684,2012$.

[100] S. S. Kelkar and T. M. Reineke, "Theranostics: combining imaging and therapy," Bioconjugate Chemistry, vol. 22, no. 10, pp. 1879-1903, 2011.

[101] E.-K. Lim, T. Kim, S. Paik, S. Haam, Y.-M. Huh, and K. Lee, "Nanomaterials for theranostics: recent advances and future challenges," Chemical Reviews, vol. 115, no. 1, pp. 327-394, 2015.

[102] R. Weissleder, "A clearer vision for in vivo imaging," Nature Biotechnology, vol. 19, no. 4, pp. 316-317, 2001.

[103] Z. Zhou, Y. Yan, K. Hu et al., "Autophagy inhibition enabled efficient photothermal therapy at a mild temperature," Biomaterials, vol. 141, pp. 116-124, 2017.

[104] L. Zou, H. Wang, B. He et al., "Current approaches of photothermal therapy in treating cancer metastasis with 
nanotherapeutics," Theranostics, vol. 6, no. 6, pp. 762-772, 2016.

[105] Z. S. Silva Jr., S. K. Bussadori, K. P. Fernandes, Y. Y. Huang, and M. R. Hamblin, "Animal models for photodynamic therapy (PDT)," Bioscience Reports, vol. 35, no. 6, 2015.

[106] J. Du, S. Yang, Y. Qiao, H. Lu, and H. Dong, "Recent progress in near-infrared photoacoustic imaging," Biosensors and Bioelectronics, vol. 191, Article ID 113478, 2021.

[107] A. Smirnov, O. V. Odintsova, V. V. Lashkul, V. V. Sharoiko, and E. V. Solovyeva, "Noble metal nanoparticles modified by cyanines and stilbenes for enhanced signal optical tomography and hyperthermal therapy," in Proceedings of the European Conference on Biomedical Optics, June 2021.

[108] Q. Chen, L. Xu, C. Liang, C. Wang, R. Peng, and Z. Liu, "Photothermal therapy with immune-adjuvant nanoparticles together with checkpoint blockade for effective cancer immunotherapy," Nature Communications, vol. 7, no. 1, Article ID 13193, 2016.

[109] O. Bar-Ilan, R. M. Albrecht, V. E. Fako, and D. Y. Furgeson, "Toxicity assessments of multisized gold and silver nanoparticles in zebrafish embryos," Small, vol. 5, no. 16, pp. 1897-1910, 2009.

[110] L. Ramteke, P. Gawali, B. L. Jadhav, and B. A. Chopade, "Comparative study on antibacterial activity of metal ions, monometallic and alloy noble metal nanoparticles against nosocomial pathogens," BioNanoScience, vol. 10, no. 4, pp. 1018-1036, 2020.

[111] R. P. Singh and P. Ramarao, "Cellular uptake, intracellular trafficking and cytotoxicity of silver nanoparticles," Toxicology Letters, vol. 213, no. 2, pp. 249-259, 2012.

[112] S. J. Kang, Y. J. Lee, E.-K. Lee, and M.-K. Kwak, "Silver nanoparticles-mediated G2/M cycle arrest of renal epithelial cells is associated with NRF2-GSH signaling," Toxicology Letters, vol. 211, no. 3, pp. 334-341, 2012.

[113] R. Foldbjerg, D. A. Dang, and H. Autrup, "Cytotoxicity and genotoxicity of silver nanoparticles in the human lung cancer cell line, A549," Archives of Toxicology, vol. 85, no. 7, pp. 743-750, 2011.

[114] D. Wang and S. J. Lippard, "Cellular processing of platinum anticancer drugs," Nature Reviews Drug Discovery, vol. 4, no. 4, pp. 307-320, 2005.

[115] P. J. Shiny, A. Mukherjee, and N. Chandrasekaran, "DNA damage and mitochondria-mediated apoptosis of A549 lung carcinoma cells induced by biosynthesised silver and platinum nanoparticles," RSC Advances, vol. 6, no. 33, pp. 27775-27787, 2016.

[116] H. D. Mai, K. Rafiq, and H. Yoo, "Nano metal-organic framework-derived inorganic hybrid nanomaterials: synthetic strategies and applications," Chemistry - A European Journal, vol. 23, no. 24, pp. 5631-5651, 2017.

[117] L. E. van Vlerken and M. M. Amiji, "Multi-functional polymeric nanoparticles for tumour-targeted drug delivery," Expert Opinion on Drug Delivery, vol. 3, no. 2, pp. 205-216, 2006.

[118] Y. J. Zhang, B. Gallis, M. Taya, S. Wang, R. J. Y. Ho, and T. Sasaki, "pH-responsive artemisinin derivatives and lipid nanoparticle formulations inhibit growth of breast cancer cells in vitro and induce down-regulation of HER family members," PLoS One, vol. 8, no. 3, Article ID e59086, 2013.

[119] J. You, R. Zhang, C. Xiong et al., "Effective photothermal chemotherapy using doxorubicin-loaded gold nanospheres that target EphB4 receptors in tumors," Cancer Research, vol. 72, no. 18, pp. 4777-4786, 2012.
[120] H. Maeda, J. Wu, T. Sawa, Y. Matsumura, and K. Hori, "Tumor vascular permeability and the EPR effect in macromolecular therapeutics: a review," Journal of Controlled Release: Official Journal of the Controlled Release Society, vol. 65 , no. 1-2, pp. 271-284, 2000.

[121] J. W. Nichols and Y. H. Bae, "EPR: evidence and fallacy," Journal of Controlled Release, vol. 190, pp. 451-464, 2014.

[122] Y. Lu and P. S. Low, "Folate-mediated delivery of macromolecular anticancer therapeutic agents," Advanced Drug Delivery Reviews, vol. 54, no. 5, pp. 675-693, 2002.

[123] T. Fan, M. Li, X. Wu, M. Li, and Y. Wu, "Preparation of thermoresponsive and $\mathrm{pH}$-sensitivity polymer magnetic hydrogel nanospheres as anticancer drug carriers," Colloids and Surfaces B: Biointerfaces, vol. 88, no. 2, pp. 593-600, 2011.

[124] P. Schulze-Lefert, M. Becker-Andre, W. Schulz, K. Hahlbrock, and J. L. Dangl, "Functional architecture of the light-responsive chalcone synthase promoter from parsley," The Plant Cell, vol. 1, no. 7, pp. 707-714, 1989.

[125] T. Thambi, S. Son, D. S. Lee, and J. H. Park, "Poly(ethylene glycol)-b-poly(lysine) copolymer bearing nitroaromatics for hypoxia-sensitive drug delivery," Acta Biomaterialia, vol. 29, pp. 261-270, 2016.

[126] T. Lammers, F. Kiessling, W. E. Hennink, and G. Storm, "Drug targeting to tumors: principles, pitfalls and (pre-) clinical progress," Journal of Controlled Release, vol. 161, no. 2, pp. 175-187, 2012.

[127] H. Holback and Y. Yeo, "Intratumoral drug delivery with nanoparticulate carriers," Pharmaceutical Research, vol. 28, no. 8, pp. 1819-1830, 2011.

[128] S. Kim, J. E. Choi, J. Choi et al., "Oxidative stress-dependent toxicity of silver nanoparticles in human hepatoma cells," Toxicology in Vitro, vol. 23, no. 6, pp. 1076-1084, 2009.

[129] S. Rana, A. Bajaj, R. Mout, and V. M. Rotello, "Monolayer coated gold nanoparticles for delivery applications," Advanced Drug Delivery Reviews, vol. 64, no. 2, pp. 200-216, 2012.

[130] D. Cassano, A.-K. Mapanao, M. Summa et al., "Biosafety and biokinetics of noble metals: the impact of their chemical nature," ACS Applied Bio Materials, vol. 2, no. 10, pp. 4464-4470, 2019.

[131] G. Crisponi, V. M. Nurchi, J. I. Lachowicz, M. Peana, S. Medici, and M. A. Zoroddu, "Chapter 18-toxicity of nanoparticles: etiology and mechanisms," in Antimicrobial Nanoarchitectonics, A. M. Grumezescu, Ed., Elsevier, Amsterdam, Netherlands, pp. 511-546, 2017.

[132] A. Zielińska, B. Costa, M. V. Ferreira et al., "Nanotoxicology and nanosafety: safety-by-design and testing at a glance," International Journal of Environmental Research and Public Health, vol. 17, no. 13, p. 4657, 2020. 